\title{
PERANCANGAN MODEL PENAKSIRAN PERFORMANSI ERGONOMI KESELAMATAN DAN KESEHATAN KERJA DI PT. PAL INDONESIA
}

\author{
Asri Dwi Puspita, Sri Gunani Partiwi, Arief Rahman
}

Manajemen Kinerja Strategies, Program Pasca Sarjana Jurusan Teknik Industri, Institut Teknologi Sepuluh Nopember, Surabaya, Indonesia

E-mail: asripuspita85@gmail.com

\begin{abstract}
Abstrak
PT. PAL Indonesia adalah perusahaan milik Negara yang bergerak dalam bidang produksi kapal niaga, kapal perang, pemeliharaan dan perbaikan kapal serta produksi rekayasa umum. Perkembangan industri saat ini menjalankan proses pengukuran kinerja keselamatan dan kesehatan kerja serta ergonomi dalam pelaksanaan proses produksinya. Permasalahan yang dihadapi dalam penelitian ini adalah bagaimana menentukan model performansi ergonomi keselamatan dan kesehatan kerja di PT. PAL INDONESIA dengan mengacu pada balanced scorecard serta dapat melakukan upaya perbaikan dalam meningkatkan performansi ergonomi keselamatan dan kesehatan kerja $(K 3)$ terhadap kinerja perusahaan. Penelitian ini bertujuan untuk mendapatkan Key Performance Indicators (KPI) yang relevan, mengetahui penyebab menurunnya performansi ergonomi K3 dengan menggunakan diagram tulang ikan, serta memperoleh rekomendasi upaya perbaikan dalam meningkatkan performansi ergonomi $\mathrm{K} 3$ terhadap kinerja perusahaan.

Hasil dari penelitian ini adalah memberikan konsep model performansi ergonomi keselamatan dan kesehatan kerja terhadap kinerja perusahaan, memberikan pengetahuan mengenai penyebab menurunnya performansi ergonomi K3 terhadap kinerja perusahaan dan membantu perusahaan dalam meningkatkan performansi ergonomi $K 3$ terhadap kinerja perusahaan.
\end{abstract}

Kata kunci: Balanced Scorecard, Key Performance Indicators, Performansi ergonomi K3

\section{PENDAHULUAN}

Dalam situasi persaingan global PT. PAL Indonesia (PERSERO) membutuhkan upaya perbaikan termasuk dengan melakukan penilaian atau evaluasi kerja. Semala ini PT. PAL Indonesia (PERSERO) telah mengukur kinerja keselamatan dan kesehatan kerja (K3) secara rapi dan terstruktur, akan tetapi pendekatan yang selama ini telah dilakukan belum menjamin perusahaan untuk menciptakan nilai ekonomis masa depan.

Program K3 harus diterapkan disemua tempat kerja karena K3 merupakan salah satu persyaratan dalam meningkatkan produktivitas kerja karyawan (Sutjana, 2006). K3 merupakan bagian dari ergonomi, dalam hal ini ergonomi juga berupaya menciptakan keselamatan dan kesehatan kerja bagi tenaga kerja. Penelitian K3 dan ergonomi selama ini masih hanya berorientasi pada hal tersebut akan tetapi belum berorientasi pada K3 dan ergonomi untuk mengetahui kontribusi aspek ergonomi terhadap kinerja perusahaan. Faktor terakhir adalah program yang dilaksanakan lebih banyak program kuratif dibandingkan dengan program preventif dan promotif sehingga tampak sebagai pengeluaran saja.

Penelitian ini akan mengevaluasi aspek ergonomic assessment, pengukuran kinerja mengacu pada metode balanced scorecard dan untuk mengetahui kontribusi aspek ergonomi terhadap kinerja perusahaan akan menggunakan diagram tulang ikan untuk mengidentifikasi kriteria yang menyebabkan menurunnya performansi pada PT. PAL Indonesia (PERSERO). Penelitian ini dapat memberikan sebuah alat untuk melakukan penilaian terhadap kinerja sehingga perusahaan dapat merencanakan dengan baik upaya strategi perbaikan dimasa depan yang terus menerus dan sistematis.

\section{METODELOGI PENELITIAN}

Latar belakang dilakukannya penelitian ini adalah memperbaiki kinerja dengan memberikan alternatif pengembangan sistem pengukuran kinerja yang dapat diaplikasikan pada pengukuran ergonomi keselamatan dan kesehatan kerja yang mengacu pada metode balanced scorecard. Langkah awal pada penelitian ini adalah mengidentifikasi keselamatan dan kesehatan kerja untuk mengetahui kondisi perusahaan.

Tahap selanjutnya melakukan pembuatan value chain dengan tujuan mengetahui jenis dan urutan kegiatan yang dilakukan oleh organisasi dalam menilai sumber daya dan kemampuan organisasi yang berkaitan dengan keselamatan dan kesehatan kerja. Setelah membuat value chain dilakukan penentuan faktor-faktor yang menjadi Strengths, Weakness, Opportunities, dan Threats yang kemudian dihubungkan dengan aktivitas di perusahaan yang ada di Value Chain, 
dari hubungan tersebut dapat ditentukan faktorfaktor SWOT untuk mencapai kinerja keselamatan dan kesehatan kerja.

Tahap terakhir adalah perancangan model performansi dengan menentukan indikator keempat dimensi pada Balanced Scorecard (Financial, Customer, Internal business Process, dan Learning and Growth). Indikator tersebut akan diberi bobot pada masing-masing perspektif dengan tujuan untuk merancang scoring pengukuran performansi. Tujuan dilakukannya scoring untuk menentukan acuan dalam perhitungan dan analisis outcome measure tiap perspektif. Gambar 1 berikut ini adalah kerangka berfikir dalam penelitian ini.

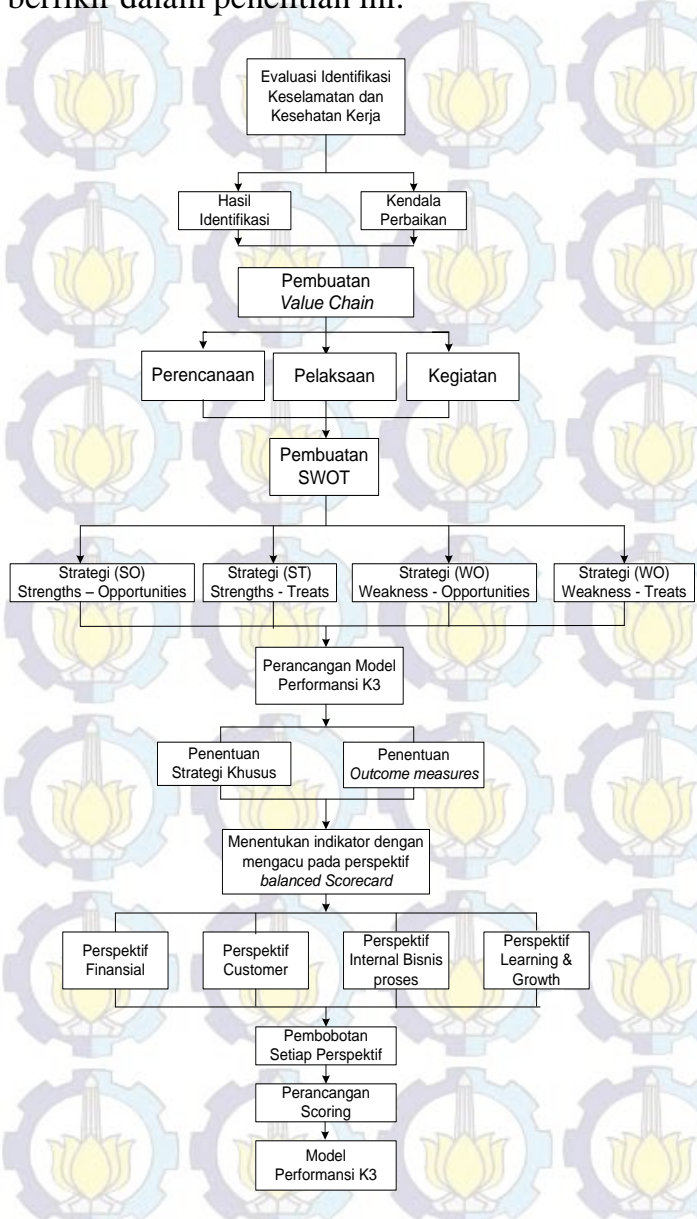

Gambar 1. Flowchart Perancangan Mode

\section{PENGOLAHAN DATA \\ PERANCANGAN MODEL}

3.1 Identifikasi Kinerja Keselamatan dan Kesehatan Kerja

Identifikasi ini dilakukan untuk mengetahui bagaimana kinerja keselamatan dan kesehatan kerja di PT. PALINDONESIA dan untuk melakukan identifikasi bahaya terhadap faktorfaktor keselamatan kerja sebagai dasar untuk ergonomic assessment. Identifikasi ini dilakukan dengan pengamatan dan pengukuran langsung pada kondisi lingkungan kerja perusahaan.
Tabel 1. Rekapitulasi Identifikasi

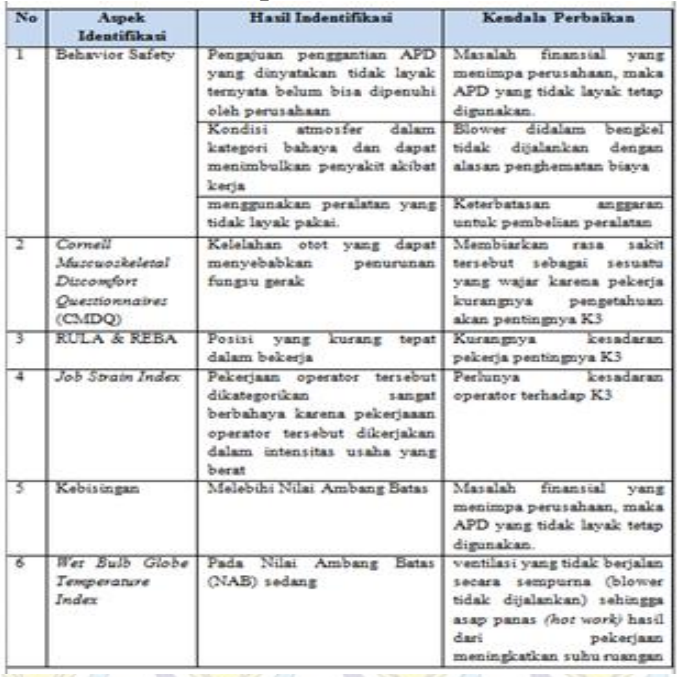

\subsection{Penyusunan Value Chain}

Setelah melakukan identifikasi keselamatan dan kesehatan kerja untuk mengetahui kondisi keselamatan dan kesehatan kerja, kemudian melakukan pembuatan Value Chain. Value Chain adalah sebuah gambaran yang menjelaskan jenis dan urutan kegiatan yang dilakukan oleh organisasi dalam mengidentifikasi dan menilai sumber daya dan kemampuan organisasi yang berkaitan dengan keselamatan dan kesehatan kerja.

\subsection{Strategi SWOT untuk Mencapai Kinerja} Keselamatan dan Kesehatan Kerja

Setelah masing-masing faktor dari Strengths, Weakness, Opportunities, dan Threats ditentukan, maka langkah selanjutnya adalah menentukan strategi yang menggabungkan keseluruhan faktor. Strategi tersebut terdiri dari Strengths - Opportunities Strategies, StrengthsThreats Strategies, Weakness-Opportunities dan Weakness-Threats Strategies.

Tabel 2. SWOT

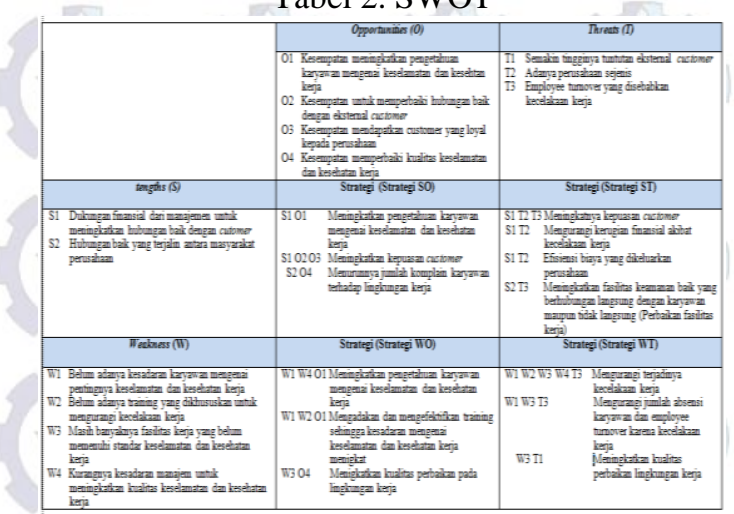

3.4 Model Performansi Ergonomi Keselamatan dan Kesehatan Kerja

Setelah menerjemahkan kekuatan (Strengths), kelemahan (Weakness), peluang (Opportunity), dan ancaman (Threats) yang 
dimiliki PT. PAL Indonesia kedalam strategi, maka langkah yang harus dilakukan selanjutnya menerjemahkan strategi tersebut ke dalam suatu sistem pengukuran performansi keselamatan dan kesehatan kerja. Agar strategi bisa diukur, maka perlu didetailkan ke dalam ukuran yang dinyatakan dengan outcome measures. Outcome measures ini berupa faktor - faktor yang dianggap penting, yang dapat dijadikan tolak ukur pengukuran performansi keselamatan dan kesehatan kerja di perusahaan.

Tabel 3. Rekapitulasi Strategi Khusus, KPI dan Perspektif

\begin{tabular}{|c|c|c|}
\hline PERSPEKIIF & STRATEGI KHUSUS & KPI \\
\hline \multirow[t]{2}{*}{ FINANCIAL } & $\begin{array}{l}\text { Mengurangi kenugian finansial yang } \\
\text { disebabkan kecelakaan kerja. }\end{array}$ & \begin{tabular}{|l} 
Biava investasi $\begin{array}{r}\text { untuk } \\
\text { kualitas }\end{array}$ \\
meningkatkan \\
keselamatan dan \\
kesesehastan
\end{tabular} \\
\hline & $\begin{array}{l}\text { Efisiensi biaya yang dikeluarkan } \\
\text { perusahaan }\end{array}$ & $\begin{array}{l}\text { Biaya yang dikcluarkann karena } \\
\text { adanya kecelakaan kerja }\end{array}$ \\
\hline \multirow{3}{*}{$\begin{array}{l}\text { INTERNAL BUSINESS } \\
\text { PROCESS }\end{array}$} & \multirow[t]{3}{*}{ Mengurangi kecelakaan ketja } & Erekuensi Kecelakan Kerja \\
\hline & & Rata-rata Hari Kerja Hilang \\
\hline & & $\begin{array}{l}\text { Tingkat Keparahan Kecelakaan } \\
\text { Kefja }\end{array}$ \\
\hline \multirow[t]{3}{*}{ CUSTOMER } & 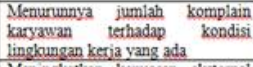 & $\begin{array}{l}\text { Jumlah komplain karyawart } \\
\text { tetkait dengan keselamatan das } \\
\text { kesechatan kerja }\end{array}$ \\
\hline & \multirow{2}{*}{$\begin{array}{l}\text { Meningkatkan kepuasan eksternal } \\
\text { customer. }\end{array}$} & Rersentass order terlambat \\
\hline & & $\begin{array}{l}\begin{array}{l}\text { Jumiah komplain konsumern } \\
\text { terkait dengan keselamatan dar } \\
\text { kesehatan kerja }\end{array} \\
\end{array}$ \\
\hline \multirow{4}{*}{$\begin{array}{l}\text { LEARNING AND } \\
\text { GROWTH }\end{array}$} & $\begin{array}{l}\text { Meningkatkan kualitas perbaikan } \\
\text { pada lingkungan kerja. }\end{array}$ & $\begin{array}{l}\text { Perbaikan tepat waktu jumlath } \\
\text { potensi bahaya yang ada }\end{array}$ \\
\hline & 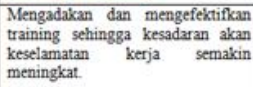 & Lumlah jenis training rutin \\
\hline & \multirow{2}{*}{$\begin{array}{l}\text { Mengurangi jumlah absenst } \\
\text { karyawan dan employee turnover } \\
\text { yang disebabkan kecelakaan kefja. }\end{array}$} & Jumlah absensi karyawan \\
\hline & & \begin{tabular}{|l|} 
Employee Turnover \\
\end{tabular} \\
\hline
\end{tabular}

\subsection{Pembobotan Performansi}

Melakukan pembobotan terhadap tiap perspektif yang terkait di dalamnya, di mana bobot ini menunjukkan tingkat kepentingan dan peranan masing-masing dalam perspektif. Adapun metode yang digunakan adalah metode Pair Comparison. Pembobotan perspektif dilakukan diskusi dengan para ahli yaitu tim HSE perusahaan. Pertama kali yang dibandingkan adalah antara financial perspektive dengan customer perspective. Tabel 4 berikut ini adalah matriks perbandingan perspektif.

Tabel 4. Matriks Perbandingan Perspektif

\begin{tabular}{|l|c|c|c|c|}
\hline & Financial & Customer & $\begin{array}{l}\text { Internal } \\
\text { Business }\end{array}$ & Learning and Growth \\
\hline Financial & 1 & 1 & 5 & 5 \\
\hline Customer & 0,3333 & 1 & 3 & 3 \\
\hline Internal Business & 0,2 & 0,3333 & 1 & 3 \\
\hline Learning and Growth & 0,2 & 0,3333 & 0,3333 & 1 \\
\hline Jumlah & 2 & 3 & 9 & 12 \\
\hline
\end{tabular}

\subsection{Perancangan Scoring Pengukuran Performansi}

Setelah bobot ditentukan, maka dilakukan perancangan scoring pengukuran performansi dimana perancangan scoring ini dilakukan untuk menentukan acuan dalam perhitungan dan analisis performansi outcome measures tiap perspektif. Perancangan ini dilakukan dengan cara diskusi bersama staf dan pimpinan HSE.

Skor yang akan diberikan untuk pengukuran performansi menggunakan skala 1 sampai 3. Skor ini ditetapkan dalam diskusi bersama staf dan pimpinan HSE. Pengertian skala 1 sampai 3 adalah sebagai berikut:

- Skor 1, artinya performansi organisasi kurang baik terhadap semua perspektif.

- Skor 2, artinya performansi organisasi cukup baik dengan kemungkinan beberapa perspektif baik dan beberapa kurang baik.

- Skor 3, artinya performansi organisasi baik terhadap semua perspektif.

Berikut ini adalah salah satu perancangan scoring yang dilakukan yaitu perancangan scoring financial perspective berisi rancangan skor untuk masing-masing outcome measures yang terdapat dalam financial perspektive.

\subsection{Pengukuran Performansi}

Setelah skor masing - masing outcome measures diperoleh selanjutnya dilakukan pengukuran dan analisis performansi pada setiap outcome measures dari tiap perspektif berdasarkan periode triwulan sesuai dengan perusahaan. Kriteria yang digunakan sebagai dasar analisis pengukuran adalah:

$1.00 \leq$ total hasil pengukuran $<1.68$ Menunjukkan kinerja organisasi kurang baik

$1.68 \leq$ total hasil pengukuran < 2.34

Menunjukkan kinerja organisasi cukup baik

$2.34 \leq$ total hasil pengukuran $\leq 3.00$ Menunjukkan kinerja organisasi baik.

Pengukuran performansi keseluruhan keselamatan dan kesehatan kerja dilakukan pada keempat perspektif pada Balanced Scorecard. Dari pengukuran keseluruhan ini dapat diketahui tingkat performansi keselamatan dan kesehatan kerja.

Tabel 5. Performansi Keseluruhan Ergonomi K3

\begin{tabular}{|c|c|c|c|c|c|}
\hline \multirow[t]{2}{*}{$\begin{array}{l}\text { Performansi } \\
\text { Keseluruhan }\end{array}$} & \multirow[t]{2}{*}{ Bobot } & \multicolumn{2}{|c|}{$\begin{array}{c}\text { Oktober - Desember } \\
2010\end{array}$} & \multicolumn{2}{|c|}{$\begin{array}{c}\text { Januari - Maret } \\
2011\end{array}$} \\
\hline & & Nilai & Jumlah & Nilai & Jumlah \\
\hline Financial & 0,4761 & 1 & 0,4761 & 2 & 0,9522 \\
\hline Customer & 0,2847 & 1,3094 & 0,3727 & 1,1097 & 0,3159 \\
\hline Internal Business & 0,1494 & 1,9998 & 0,2987 & 1,9998 & 0,2987 \\
\hline Learning and Growth & 0,0899 & 2,0001 & 0,1798 & 1,8949 & 0,1703 \\
\hline & & Total & 1,3273 & 7,0044 & 1,7371 \\
\hline
\end{tabular}

hasil performansi keseluruhan keselamatan dan kesehatan kerja pada Oktober - Desember 2010 dikategorikan kurang baik, dimana nilai yang diperoleh adalah 1, 3273. Sedangkan Januari maret 2011 dikategorikan cukup baik dengan nilai 1, 7371. Jadi performansi keseluruhan mengalami peningkatan dengan dukungan perspektif learning and growth.

3.8 Model Penaksiran Performansi Ergonomi Keselamatan dan Kesehatan Kerja

Setelah melakukan tahapan perancangan model performansi maka diperoleh model Performasi Keselamatan Kesehatan Kerja tersebut: 


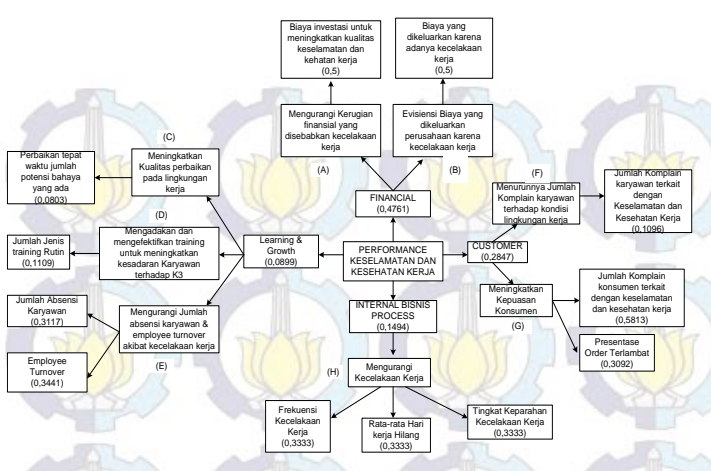

Gambar 2. Model Penaksiran Performansi K3

Model tersebut dirumukan dengan dengan rumus fungsi sebagai berikut:

$$
\begin{aligned}
\mathrm{PK}= & 0,4761 \mathrm{FC}+0,2847 \mathrm{CT}+0,1494 \mathrm{IB}+ \\
& 0,0899 \mathrm{LG} \\
= & 0,4761(\mathrm{~A}+\mathrm{B})+0,2847(\mathrm{~F}+\mathrm{G})+0,1494 \\
& \mathrm{H}+0,0899(\mathrm{C}+\mathrm{D}+\mathrm{E}) \\
= & 0,4761\left(0,5 \mathrm{~A}_{1}+0,5 \quad \mathrm{~B}_{1}\right)+0,1494 \\
& \left(0,1096 \mathrm{~F}_{1}+\left(0,5813 \mathrm{G}_{1}+0,3092 \mathrm{G}_{2}\right)\right)+ \\
& 0,1494\left(0,3333 \mathrm{H}_{1}+0,3333 \mathrm{H}_{2}+\right. \\
& \left.0,3333 \mathrm{H}_{3}\right)+0,0899\left(0,0803 \mathrm{C}_{1}+0,1109\right. \\
& \left.\mathrm{D} 1+\left(0,3117 \mathrm{E}_{1}+0,3441 \mathrm{E}_{2}\right)\right)
\end{aligned}
$$

Keterangan:

$\mathrm{FC}=$ Perspektif Finansial

$\mathrm{CT}=$ Perspektif Customer

$\mathrm{IB}=$ Perspektif Internal Bisnis Proses

LG $=$ Perspektif learning and Growth

\subsection{Perbaikan Kinerja Keselamatan dan Kesehatan Kerja}

Berdasarkan outcome measures kemudian dilakukan pencarian faktor yang menjadi penyebabnya dengan bantuan diagram tulang ikan. Beriku ini salah satu perbaikan pada financial perspektive. Outcome measures adalah biaya yang dikeluarkan karena adanya kecelakaan kerja. Faktor - faktor yang menyebabkan meningkatnya outcome measures biaya yang dikeluarkan karena adanya kecelakaan kerja yaitu adanya kecelakaan kerja yang terjadi. Akibat dari kecelakaan perusahaan harus mengeluarkan biaya untuk mengganti kerusakan yang terjadi dan sebagai biaya kompensasi karyawan yang mengalami kecelakaan. Kecelakaan kerja yang terjadi ini disebabkan lingkungan kerja yang tidak memenuhi standar keselamatan dan kesehatan kerja.

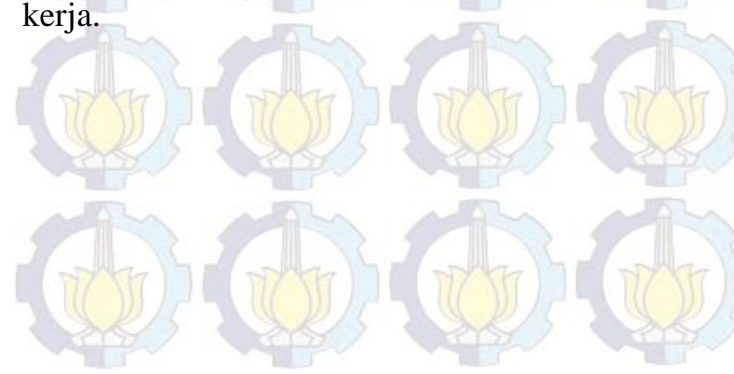

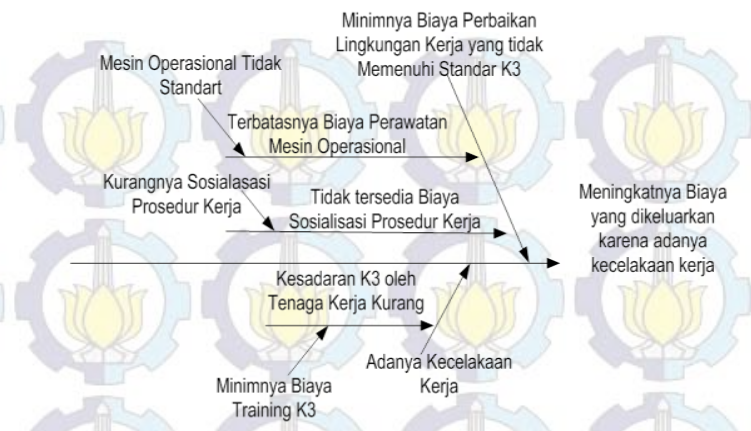

Gambar 3. Diagram Tulang Ikan Meningkatnya Biaya yang Dikeluarkan karena Adanya Kecelakaan Kerja.

\section{KESIMPULAN DAN SARAN}

- Model yang dibangun berdasarkan empat perspektif balance scorecard yaitu Financial, customer, internal business process, dan learning and growth. Empat perspektif tersebut menghasilkan KPI antara lain, pada financial menghasilkan 2 KPI, customer menghasilkan 3 KPI, internal business process menghasilkan 3 KPI dan learning and growth menghasilkan $3 \mathrm{KPI}$.

- Rumusan model Performasi Keselamatan Kesehatan Kerja tersebut:

$$
\begin{aligned}
\mathrm{PK}= & 0,4761 \mathrm{FC}+0,2847 \mathrm{CT}+0,1494 \\
& \mathrm{IB}+0,0899 \mathrm{LG} \\
= & 0,4761(\mathrm{~A}+\mathrm{B})+0,2847(\mathrm{~F}+\mathrm{G})+ \\
& 0,1494 \mathrm{H}+0,0899(\mathrm{C}+\mathrm{D}+\mathrm{E}) \\
= & 0,4761\left(0,5 \mathrm{~A}_{1}+0,5 \mathrm{~B}_{1}\right)+0,1494 \\
& \left(0,1096 \mathrm{~F}_{1}+\left(0,5813 \mathrm{G}_{1}+\right.\right. \\
& \left.\left.0,3092 \mathrm{G}_{2}\right)\right)+0,1494\left(0,3333 \mathrm{H}_{1}+\right. \\
& \left.0,3333 \mathrm{H}_{2}+0,3333 \mathrm{H}_{3}\right)+0,0899 \\
& \left(0,0803 \mathrm{C}_{1}+0,1109 \mathrm{D} 1+(0,3117\right. \\
& \left.\left.\mathrm{E}_{1}+0,3441 \mathrm{E}_{2}\right)\right)
\end{aligned}
$$

Keterangan:

$\mathrm{FC}=$ Perspektif Finansial

$\mathrm{CT}=$ Perspektif Customer

IB $=$ Perspektif Internal Bisnis Proses

LG $=$ Perspektif learning and Growth

- Rekomendasi dari upaya perbaikan performansi keselamatan dan kesehatan kerja prioritas perbaikan dalam meningkatkan kinerja keselamatan dan kesehatan kerja adalah mengadakan dan mengefektifkan training sehingga kesadaran keselamatan dan kesehatan kerja meningkat. 


\section{DAFTAR PUSTAKA}

Asfahl, C. (1999). Industrial safety and health management - 4th edition (Vols. chapter: 5,7,12). New Jersey: PrenticeHall.Inc.

Bridger, Robert. 1995. Introduction to ergonomis. New York: McGraw - Hill, Inc.

Chaudhry, A. M. 1999. To Be a ProblemSolver, Be a Classicist. Quality Progress Vol. 32, No. 6, pp. 47-51, The American Society for Quality (ASQ), Wisconsin.

Ervil, Rico. (2010). Pengembangan Model Pengukuran Kinerja Supply Chain Berbasis Balanced Scorecard. Thesis Teknik Industri. Institut Teknologi Sepuluh Nopember Surabaya.

Hendrick, H.W. 1987. Macroergonomi A Consep Whose Time has Come. Human Factor Society Bulletin, February 1987.

Sudiajeng, Lilik dan Jokodaryanto. (2007). Evaluasi Terhadap Organisasi Dan Sistem Kerja Melalui Pendekatan Ergonomi Total Pada PT.Garuda Angkasa Unit Cargo Internasional Bandar Udara Ngurah Rai Denpasar, Bali. Prosiding Seminar Nasional Ergonomi Dan K3. Fakultas Teknologi Industri, Universitas Katolik Parahyangan, Bandung.

Widodo, Lamto. 2007. Konsep Self Organizing Sisten Dan Need Fulfill Compensation Dalam Pendekatan Ergonomi Makro Sebuah Tinjauan Filosofis. Prosiding Seminar Nasional Ergonomi 2007 Integrasi Ergonomi Di Dalam Product Development. Bandung

Wignjosoebroto, S. (2003). Ergonomi Studi Gerak dan Waktu. Surabaya: Guna Widya.

www.OSHA.gov. (n.d.). Retrieved March 20, 2008, from Occupational safety and health administration (OSHA): www.osha.gov
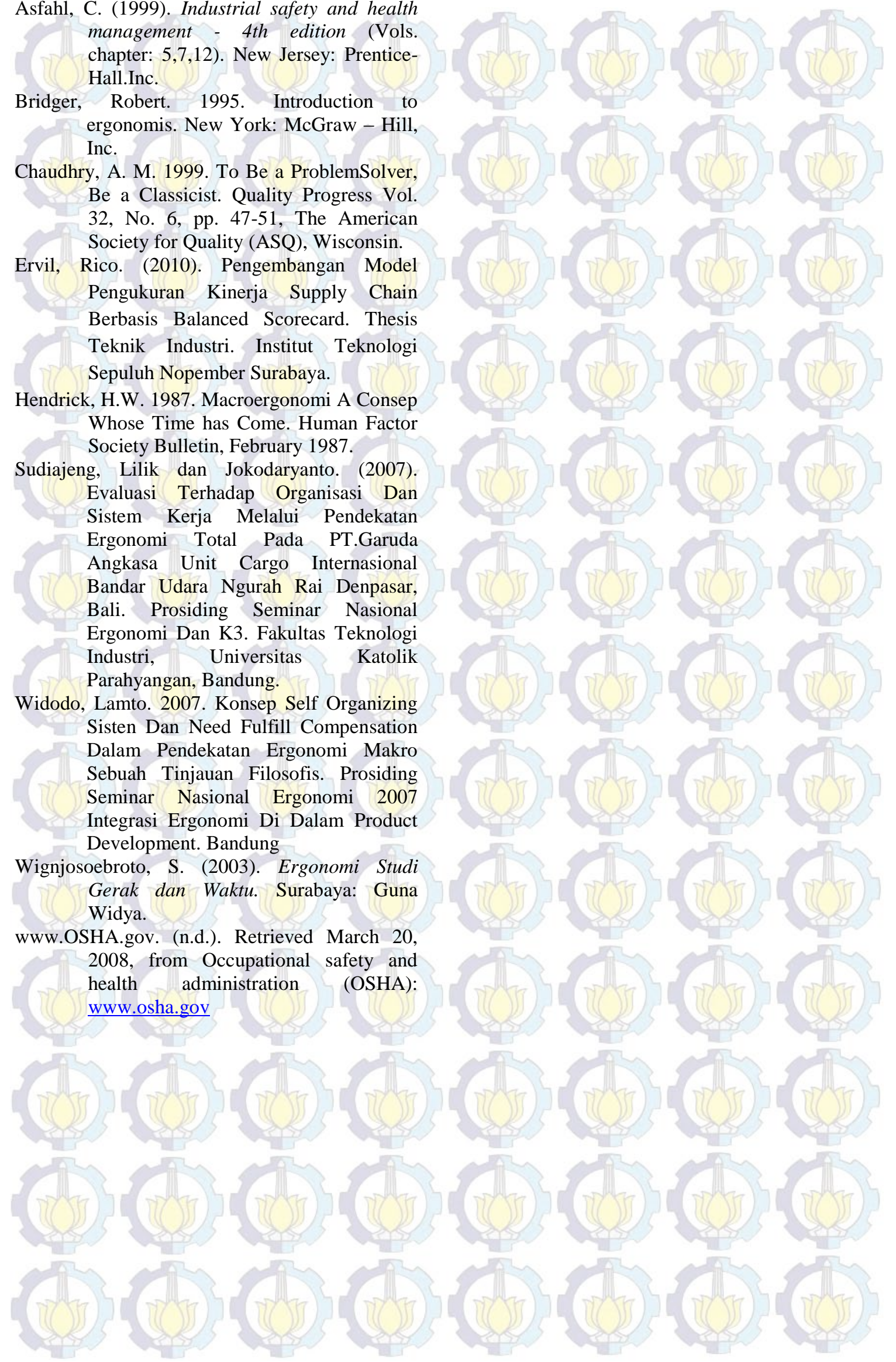

?

2.

5

र
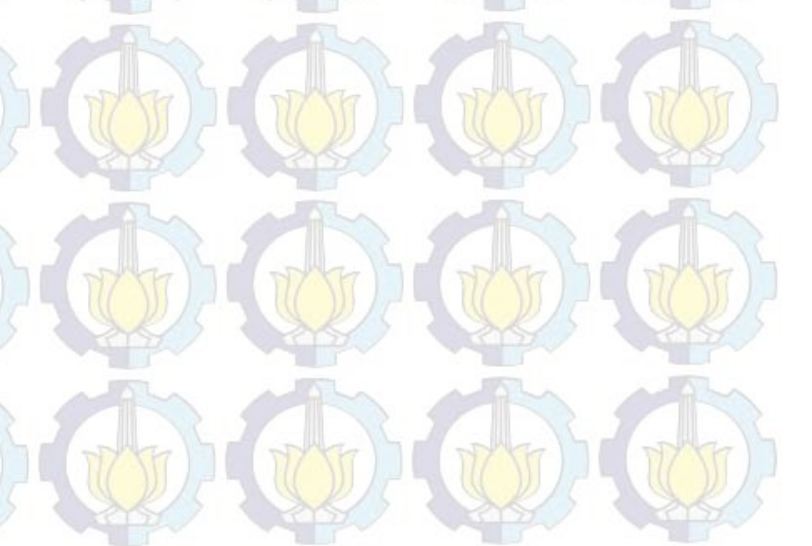